\title{
Digital Technology Needs in Maternal Mental Health: A Qualitative Inquiry
}

\author{
Alexandra ZINGG ${ }^{\mathrm{a}, 1}$, Laura CARTER ${ }^{\mathrm{a}}$, Deevakar ROGITH ${ }^{\mathrm{a}}$, Amy FRANKLIN ${ }^{\mathrm{a}}$, \\ Sudhakar SELVARAJ $^{\mathrm{b}}$, Jerrie REFUERZO ${ }^{\mathrm{c}}$ and Sahiti MYNENI ${ }^{\mathrm{a}}$ \\ ${ }^{a}$ School of Biomedical Informatics, University of Texas Health Science Center at \\ Houston, Houston, Texas, USA \\ ${ }^{\mathrm{b}}$ Faillace Department of Psychiatry and Behavioral Sciences, University of Texas \\ Health Science Center at Houston, McGovern Medical School, Houston, Texas, USA \\ ${ }^{c}$ UT Physician's Women's Center, University of Texas Health Science Center at \\ Houston, Houston, Texas, USA
}

\begin{abstract}
Digital technologies offer many opportunities to improve mental healthcare management for women seeking pre- and-postnatal care. They provide a discrete, practical medium that is well-suited for the sensitive nature of mental health. Women who are more prone to experiencing peripartum depression (PPD), such as those of low-socioeconomic background or in high-risk pregnancies, can benefit the most from such technologies. However, current digital interventions directed towards this population provide suboptimal support, and their responsiveness to end user needs is quite limited. Our objective is to understand the digital terrain of information needs for low-socioeconomic status women with high-risk pregnancies, specifically within the management of their mental health. This qualitative study consists of semi-structured focus groups and interviews with a sample of nineteen patients. A total of eleven core themes emerged from participant comments. Resulting themes highlighted the need for digital technologies that promote personalized care, a sense of community, and improved provider communication.
\end{abstract}

Keywords. pregnancy; postpartum; mental health; mobile apps; connected health

\section{Introduction}

Perinatal women with low education and income tend to have low depression literacy, reducing their ability to recognize depression symptoms [1]. Additionally, more than $90 \%$ of women who experience depression in low- and - middle income countries lack access to treatment [2]. Digital technologies are seen as a viable solution to address some of these disparities [3], as they can help address information and social support gaps during the pregnancy journey [4]. Few studies have focused on the development and implementation of digital technology interventions among low socioeconomic status (SES) and minority women to address disparities in peripartum depression (PPD) care $[5,6]$, which reveal that digital technology efforts towards reducing health disparities in PPD can significantly improve mental health outcomes for these populations. Integrating potential end-users in the development process of digital technologies has resulted in

\footnotetext{
${ }^{1}$ Corresponding Author, Alexandra Zingg, School of Biomedical Informatics, University of Texas Health Science Center at Houston, Houston, Texas, USA; E-mail: Alexandra.q.zinggguzman@uth.tmc.edu.
} 
engaging products that prevent inequities in digital health technology use [7]. However, research on how best to leverage digital technologies to reduce disparities in PPD literacy and access to care is scarce [8]. Thus, the purpose of this study is to contribute to existing knowledge by characterizing the information and socio-technical needs of low-SES peripartum women in high-risk pregnancies to formulate and engineer responsive digital technologies for the underserved communities that are plagued with health disparities.

\section{Methods}

Data Collection: Two focus group sessions were held with nine participants, and 10 additional participants were individually interviewed. Focus groups were conducted in May 2019 and interviews in October and November of 2020. All participants completed a survey prior to the focus group or interview. This survey collected data on participants' demographics, socioeconomics, information access, and prior pregnancy-related health experiences. Focus groups and interviews followed a semi-structured format where topic questions were used to guide discussion. These questions were designed to reveal themes about topics such as participants' use of technology and their knowledge of depression (example questions: Do you use any mobile apps or any social media platforms to educate yourselves regarding your pregnancy? Even before you were pregnant, were you ever educated on the possibility of being anxious, depressed, sad?). Focus groups and interview guides consisted of the same questions, but interviews additionally asked participants to expand on technology design preferences (i.e., graphics, survey designs). Recruitment took place at an academic Maternal-Fetal Medicine (MFM) clinic in Houston, Texas. Participants had to be at least 18 years old, English speaking, and currently seeking pre- or post-natal care at the clinic. This study was approved by IRB HSC-SBMI-18-1003 from the University of Texas Health Science Center at Houston.

Data Analysis: Focus groups and interviews were recorded, and themes were inductively extracted through grounded theory analysis [9]. The first step in this process was to openly code each comment, whereby each line was analyzed to derive concepts [10]. Open codes were dynamically produced as the comments were analyzed. Examples of open codes included "group" and "miscarriage". Open coding was conducted until no new concepts emerged. The second step was to perform axial coding, where patterns and relationships among the open codes were discovered [10]. Axial coding allowed for the discovery of major themes, including "Community Environment," and "Coping with prior pregnancy". As example of our axial coding process, we grouped the open codes of "group", "local", and "camaraderie" into the theme of "Community Environment". These themes inform prototype design to incorporate preferred PPD management content through human-centered design processes by (a) gathering and understanding women's needs for mental health management, (b) defining evidence-based PPD care concepts, beliefs, and barriers, and (c) ideating desired features for maternal mental digital health.

\section{Results}

Most participants were young: 10 were 25-34 years old, five were 18-24 years old, and four were 35-44 years old. The ethnical composition of our sample was: seven identified as Hispanic, six as Black, four as White, one as Asian, and one as Other. One participant had an education level of some high school, three participants were high school graduates, 
five participants had some college credit, five had an associate's degree, four had received technical training, and one had a bachelor's degree. 14 out of 19 participants were low-income women. 13 participants had experienced depression or similar symptoms in their current pregnancy. Of these, seven had talked to their doctor. 10 participants had experienced depression symptoms in previous pregnancies. 15 of 19 participants reported owning a cell phone. The main source of pregnancy information for participants was the internet $(\mathrm{n}=17) .11$ participants reported seeking additional information from non-digital sources like their doctors, friends, and family.

Our focus group analysis produced 40 unique open codes and six core themes. These ranged from personal beliefs and experiences, to clinical and social factors in PPD selfmonitoring and management (Table 1). Themes included a desire to have better streamlined communication channels within clinics for improved information exchange with providers, and to manage documents such as lab results. The ability to build local communities with women who have had similar pregnancy experiences was seen as an advantage of digital tools. Participants also stated that current technology products in the market did not cover much information about mental health during pregnancy.

Table 1. Focus Group Themes and Comments

\begin{tabular}{|c|c|c|}
\hline Theme & Definition & Sample comment \\
\hline $\begin{array}{l}\text { Open and timely } \\
\text { communication } \\
\text { with providers }\end{array}$ & $\begin{array}{l}\text { Comments that express a desire of } \\
\text { being able to receive information from } \\
\text { providers at the right time. }\end{array}$ & $\begin{array}{l}\text { "[If your doctor can see your journal } \\
\text { entries from an app] they will see you as a } \\
\text { human, not just as a patient. They will know } \\
\text { "This patient is really concerned, so let's } \\
\text { not wait to answer this question, let's call } \\
\text { them right now" }\end{array}$ \\
\hline $\begin{array}{l}\text { Community } \\
\text { environment }\end{array}$ & $\begin{array}{l}\text { Comments that express a need to } \\
\text { connect with fellow perinatal women } \\
\text { to form friendships and support } \\
\text { groups. }\end{array}$ & $\begin{array}{l}\text { "Having someone [a fellow app user] say } \\
\text { 'Hey, let me bring you some food and let's } \\
\text { have a talk' even though we don't want to } \\
\text { talk and want to shut down, in a sense that } \\
\text { can help you get through it" }\end{array}$ \\
\hline $\begin{array}{r}\text { Personalized } \\
\text { support }\end{array}$ & $\begin{array}{l}\text { Comments where participants } \\
\text { mentioned a need for technology that } \\
\text { considered their unique pregnancy } \\
\text { experiences }\end{array}$ & $\begin{array}{l}\text { "The apps aren't really personalized. } \\
\text { They're general, they're like, average. Me, } \\
\text { I have [medical condition], so it's not } \\
\text { designed for people like me" }\end{array}$ \\
\hline $\begin{array}{l}\text { Coping with prior } \\
\text { pregnancy } \\
\text { outcomes }\end{array}$ & $\begin{array}{l}\text { Comments that denote the need for } \\
\text { technology to help cope with adverse } \\
\text { pregnancy outcomes. }\end{array}$ & $\begin{array}{l}\text { "For people who have had several } \\
\text { miscarriages, they can talk to someone } \\
\text { [who has gone through a similar experience } \\
\text { through the app]" }\end{array}$ \\
\hline $\begin{array}{l}\text { Problems with } \\
\text { information silos }\end{array}$ & $\begin{array}{l}\text { Comments that express gaps in } \\
\text { communication and information } \\
\text { between the patient and provider. }\end{array}$ & $\begin{array}{l}\text { "One of the interns gave his student email } \\
\text { to ask him questions, because I couldn't get } \\
\text { ahold of anybody here" }\end{array}$ \\
\hline $\begin{array}{c}\text { Barriers to mental } \\
\text { health care }\end{array}$ & $\begin{array}{l}\text { Comments where participants } \\
\text { describe difficulties receiving access } \\
\text { to care due to socioeconomic factors } \\
\text { such as insurance. }\end{array}$ & $\begin{array}{l}\text { "I work in the medical field...it's contracts. } \\
\text { If they [your insurance] don't have a } \\
\text { contract with that hospital, forget it. It's } \\
\text { frustrating because sometime you have to } \\
\text { go to that hospital." }\end{array}$ \\
\hline
\end{tabular}

Our interviews produced 47 open codes that were grouped into five overarching themes. These provide insights into technology design elements related to content creation, health literacy, patient engagement, and human factors engineering:

Specialized information systems to manage high-risk pregnancies: In alignment with focus group results, our interviews showed that patients were seeking technology products specific to unique pregnancies. This is illustrated in interview comment I1.

I1: "Since we're MFM, it's different than a typical pregnancy. Would be nice if in the app we could check his statistics, like femur length, tibia length, weight, week for 
week to see how he is developing. That would be reassuring [...]. I think that would be more meaningful, for not your typical pregnancy but in MFM, where we see a specialist. There isn't anything currently on the market.".

Fast Digestible Education Materials: Participants desired educational materials presented in fast and easy to digest formats, such as videos (I2) or slide shows. Overall, participants were lenient to formats that fitted their busy lifestyles as mothers.

I2: "Videos. I would include videos and wording on it. The topics I would include would be mental health, and just in general any information about pregnancy. I would look for research studies".

Information Credibility: While participants recognized that apps could provide valuable information, they preferred to refer to their doctor if they needed more detailed or specific information (I3). Some indicated that they would be skeptical of the app if they couldn't verify its information source.

13: "Sometimes the apps have good information, but I mean, I would also like to sit down and talk with the doctor over here, for more feedback and things like that. If I have something to be answered, I would trust the doctor rather than the app".

Minimalist design: Participants preferred technology designs that were simple and informative. They coincided in wanting visual ways of indicating their current state of mind, such as pictures and colors. Many would use self-monitoring tools such as mental health surveys provided these had a limited number of questions (i.e., five questions) and could be completed in a fast manner (i.e., under five minutes).

Affordable Tech: Factors that played into consideration when purchasing apps were previous user reviews and the functionality that the app offered. Two interviewees stated they would not consider any apps which included a price, while the rest would consider apps with low prices (i.e., \$5).

\section{Discussion}

Participants mentioned themes that aligned with previous studies [i.e., 11], and also revealed several notions to be cognizant of during development and design of digital tools for maternal mental health. Most of our sample was young, indicating that technologies for maternal mental health should be developed for a generation that is lenient towards digital tools in their everyday routines. Participants reported having no digital tools which provided personalized support. This was important to them, as many had pregnancy conditions such as gestational diabetes and previous early births. They reported that most technologies were designed for "perfect pregnancies". Therefore, emerging digital platforms would have to be designed to consider each individual's medical history and social characteristics (i.e., previous PPD history). Limitations of our study include a low sample size, and that our sample was comprised of women who were at higher risk for PPD and only included English-speaking women. This may limit the generalizability of our results. However, the purpose of this formative study was to conduct an initial assessment of our target population's information needs during the peripartum period. Next steps in our research program will be to triangulate optimal design paradigm for effective and efficient self-management and care coordination for PPD and other mental health issues. 


\section{Conclusions}

In this study, we document the opinions of perinatal women regarding digital technology use for their mental health management. Specialized digital technologies that focus on mental health needs and offer personalization and coping abilities are integral to effective and efficient self-management and care coordination for PPD. Future studies on this important health issue can benefit from leveraging digital health and analytics to address health disparities and create sustainable patient-facing collaborative care solutions.

\section{Acknowledgements}

This research was partly supported by the National Library of Medicine of the National Institutes of Health under award numbers 1R01LM012974-01A1. The content is solely the responsibility of the authors and does not necessarily represent the official views of the National Institutes of Health.

\section{References}

[1] Fonseca A, Silva S, Canavarro MC. Depression Literacy and Awareness of Psychopathological Symptoms During the Perinatal Period. J Obstet Gynecol Neonatal Nurs. 2017 Mar-Apr;46(2):197-208. doi: 10.1016/j.jogn.2016.10.006. Epub 2017 Jan 9. PMID: 28082210.

[2] Rahman A, Waqas A, Nisar A, Nazir H, Sikander S, Atif N. Improving access to psychosocial interventions for perinatal depression in low- and middle-income countries: lessons from the field. International Review of Psychiatry. 2020 Jun 9;0(0):1-4.

[3] Roundtable on the Promotion of Health Equity and the Elimination of Health Disparities; Board on Population Health and Public Health Practice; Health and Medicine Division; National Academies of Sciences, Engineering, and Medicine. The Promises and Perils of Digital Strategies in Achieving Health Equity: Workshop Summary. Washington (DC): National Academies Press (US); 2016 Jun 22. 2, Technology and Health Disparities. Available at: www.ncbi.nlm.nih.gov/books/NBK373436/.

[4] Peyton T, Poole E, Reddy M, Kraschnewski J, Chuang C. Information, sharing and support in pregnancy: addressing needs for mHealth design. In: Proceedings of the companion publication of the 17th ACM conference on Computer supported cooperative work \& social computing [Internet]. New York, NY, USA: Association for Computing Machinery; 2014. p. 213-6. (CSCW Companion '14). Available at: https://doi.org/10.1145/2556420.2556489, Accessed 2021 Feb 28.

[5] Gordon M, Henderson R, Holmes JH, Wolters MK, Bennett IM, Group the S (Stress in PIR with IT. Participatory design of ehealth solutions for women from vulnerable populations with perinatal depression. J Am Med Inform Assoc. 2016 Jan 1;23(1):105-9.

[6] Broom MA, Ladley AS, Rhyne EA, \& Halloran DR. Feasibility and Perception of Using Text Messages as an Adjunct Therapy for Low-Income, Minority Mothers With Postpartum Depression. JMIR mental health; 2015, 2(1), e4. doi:10.2196/mental.4074. PMID: 26543910.

[7] Brewer LC, Fortuna KL, Jones C, Walker R, Hayes SN, Patten CA, et al. Back to the Future: Achieving Health Equity Through Health Informatics and Digital Health. JMIR mHealth and uHealth. 2020;8(1):e14512.

[8] Dosani A, Arora H, Mazmudar S. mHealth and perinatal depression in low-and middle-income countries: a scoping review of the literature. International journal of environmental research and public health. 2020;17(20):7679.

[9] Harrell M, Bradley M. Data Collection Methods: Semi-Structured Interviews and Focus Groups. RAND Corporation; 2009.

[10] Rieger KL. Discriminating among grounded theory approaches. Nursing Inquiry. 2019;26(1):e12261.

[11] Doherty K, Barry M, Marcano-Belisario J, Arnaud B, Morrison C, Car J, Doherty G. A Mobile App for the Self-Report of Psychological Well-Being During Pregnancy (BrightSelf): Qualitative Design Study. JMIR mental health. 2018;5(4):e10007. doi:10.2196/10007. PMID: 30482742. 